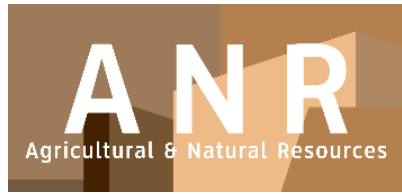

PAPER - OPEN ACCESS

\title{
Peranan Restorasi Hutan dalam Konservasi Jenis Mangrove di Pesisir Timur Sumatera Utara
}

\author{
Author \\ : Onrizal \\ DOI \\ : 10.32734/anr.v1i2.230 \\ Electronic ISSN \\ : 2654-7023 \\ Print ISSN \\ : 2654-7015 \\ Volume 1 Issue 2 - 2018 TALENTA Conference Series: Agricultural \& Natural Resources (ANR)
}

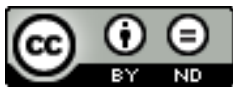

This work is licensed under a Creative Commons Attribution-NoDerivatives 4.0 International License.

Published under licence by TALENTA Publisher, Universitas Sumatera Utara
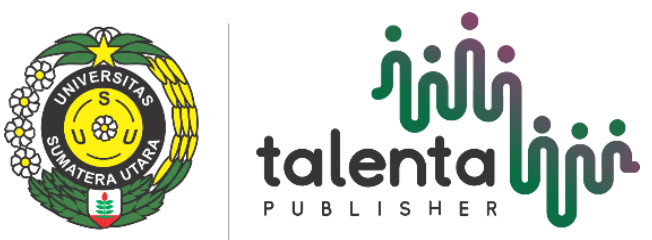


\title{
Peranan Restorasi Hutan dalam Konservasi Jenis Mangrove di Pesisir Timur Sumatera Utara
}

\author{
Rizka Amelia $^{\text {a }}$, Onrizal ${ }^{\text {a* }}$, Nurdin Sulistiyono $^{\text {a }}$, Muhammad Arif ${ }^{\text {a }}$, Rika Agustini ${ }^{a}$, Greys \\ N. Simamora ${ }^{a}$, Jon M. Saragih ${ }^{\mathrm{a}}$, Risky K. Saragih ${ }^{\mathrm{a}}$ \\ Fakultas Kehutanan, Universitas Sumatera Utara, Medan 20155, Indonesia
}

onrizal@usu.ac.id

\begin{abstract}
Abstrak
Hutan mangrove merupakan sumber daya lahan basah yang berfungsi sebagai penyangga kehidupan. Namun demikian, dalam beberapa dekade terakhir, hutan mangrove banyak yang rusak atau hilang, terutama akibat konversi mangrove menjadi lahan tambak. Kegiatan restorasi mangrove pada lahan bekas tambak telah mulai dilakukan dalam beberapa tahun terakhir. Peneltian ini bertujuan untuk mengukur pemulihan jenis-jenis mangrove melalui kegiatan restorasi mangrove pada lahan bekas tambak serta mengetahui komposisi jenis hutan mangrove hasil restorasi dimaksud di pesisir timur Sumatera Utara. Sebanyak 30 plot contoh yang masing masing berukuran $10 \mathrm{~m} \times 10 \mathrm{~m}$ telah dibangun di setiap umur tegakan (5-9 tahun) dan hutan sekunder. Seluruh pohon yang berdiameter $(\mathrm{DBH}) \geqslant 2 \mathrm{~cm}$ di dalam plot contoh diidentifikasi dan diukur diamaternya. Secara keseluruhan, terdapat 14 jenis mangrove pada seluruh plot contoh atau setara dengan $42,42 \%$ dari seluruh jenis tumbuhan mangrove sejati yang terdapat di Indonesia. Dengan demikian, restorasi mangrove mampu memulihkan keanekaragaman jenis mangrove, sehingga restorasi mangrove pada lahan bekas tambak perlu dipromosikan dalam upaya mengembalikan berbagai fungsi mangrove bagi ketahanan masyarakat dan sumberdaya pesisir.
\end{abstract}

Kata Kunci: Type your keywords here, separated by semicolons ;

\section{Pendahuluan}

Hutan mangrove seara alami tumbuh di pesisir pantai tropis dan sebagian sub tropis yang mendukung berbagai layanan ekosistem, termasuk produksi perikanan, siklus hara, siklus nutrisi, pembentukan tanah, produksi kayu, tempat bertelur ikan, ekowisata dan penyimpanan karbon (C) [1]. Total luas hutan mangrove dunia pada tahun 2000 adalah $137.760 \mathrm{~km} 2$ dan 22,6\% diantaranya berada di Indonesia [2]. Dalam tiga dekade terakhir, kerusakanhutan karena faktor antropogenik telah meningkat secara signifikan. Hutan mangrove yang tersisa terancam akibat tebang habis, konversi lahan, perubahan hidrologi, tumpahan bahan kimia dan perubahan iklim [2].

Pada akhir tahun 1960-an, Indonesia telah kehilangan lebih dari 200.000 hektar hutan mangrove. Oleh karena adanya kebijakan dari pemerintah untuk memperluas tambak pada era 1980an yang memicu kehilangan luas mangrove sebanyak 800.000 ha hanya dalam 30 tahun [3]. Semantara itu sekitar 60\% hutan mangrove di pesisir timur Sumatera Utara telah hilang dalam kurun waktu 1977-2006, terutama akibat konversi menjadi lahan tambak [4]. 
Kehilangan dan kerusakan hutan mangrove di suatu wilayah akan menurunkan produktivitas mangrove dalam mendukung ekosistem pesisir yang akan menimbulkan berbagai persoalan lingkungan seperti banjir, intruksi air laut, abrasi pantai, penurunan volume dan keragaman jenis ikan yang ditangkap [4]. Upaya restorasi mangrove pada lahan tambak yang sudah tidak produktif atau lahan bekas tambak telah dilakukan pada beberapa wilayah di pesisir timur Sumatera Utara sejak akhir 2000an. Penelitian ini bertujuan untuk mengukur pemulihan jenis-jenis mangrove akibat kegiatan restorasi mangrove dan menetahui komposisi jenis pada berbagai umur tegakan hutan mangrove hasil restorasi pada lahan bekas tambak.

\section{Bahan dan Metode}

\subsection{Lokasi Penelitian}

Penelitian ini dilaksanakan di hutan mangrove hasil restorasi pada lahan bekas tambak di Kecamatan Percut Sei Tuan, Kabupaten Deli Serdang, Provinsi Sumatera Utara.

\subsection{Metode}

Penelitian lapangan dilakukan dalamperiodeSeptember - Desember 2016. Analisis vegetasi mengikuti metode petak dengan unit contoh sebanyak 30 buah di setiap umur tegakan dengan ukuran masing-masing $10 \mathrm{x} 10 \mathrm{~m}$. Pemilihan petak tegakan menurut umur dilakukan secara purposif dan jarak antar petak contoh di setiap umur adalah $10 \mathrm{~m}$. Setiap pohon di petak contoh dikelompokkan berdasarkan tingkat pertumbuhan, yaitu 1) anakan pohon yang berdiameter 2,0-9,9 $\mathrm{cm}$ dan 2) pohon yang berdiameter $\geqslant 10 \mathrm{~cm}$. Setiap individu yang terdapat di dalam setiap plot diidentifikasi, dan diukur diameternya (DBH), ditaksir tinggi total pohon (TT) mengacu pada Onrizal dan Mansor [5].

Dominansi jenis tumbuhan ditentukan dari Indeks Nilai Penting (INP) dengan rumus sebagai berikut:

$$
\begin{gathered}
\text { Kerapatan Jenis }(K ; \text { ind } / h a)=\frac{\sum \text { jumlah individu spesies }-i}{\text { luas petak contoh }} \\
\text { Kerapatan Relatif }(K R ; \%)=\frac{\sum \text { Kspesies }-i}{\text { Ktotal seluruh jenis }} \times 100 \% \\
\text { Frekuensi }(F)=\frac{\sum \text { sub petak ditemukan spesies }-i}{\sum \text { seluruh sub petak contoh }} \\
\text { Frekuensi Relatif }(F R ; \%)=\frac{F \text { spesies }-i}{\text { Ftotal seluruh jenis }} \times 100 \% \\
\text { Dominansi }\left(D ; m^{2} / h a\right)=\frac{\text { Lbdsspesies }-i}{\text { Luas petak contoh }} \\
\text { Dominansi Relatif }(D R ; \%)=\frac{\text { Dspesies }-i}{\text { Dtotal seluruh spesies }} \times 100 \%
\end{gathered}
$$

INP untuk tingkat pohon $=\mathrm{KR}+\mathrm{FR}+\mathrm{DR}$ dan untuk tingkat anakan pohon $=\mathrm{KR}+\mathrm{FR}$.

\section{Hasil}

\subsection{Sebaran Jenis-Jenis Mangrove}

Sebanyak 14 jenis pohon mangrove yang dijumpai di seluruh petak contoh, dimana pada tingkat pohon terdiri dari 11 jenis dan anakan pohon sebanyak 13 jenis. Semua jenis mangrove yang dijumpai tersebut tergolong jenis-jenis mangrove sejati. Dengan demikian, dengantotal plot contoh seluas 1,8 ha terdapat sekitar $42,42 \%$ jenis dari seluruh jenis tumbuhan mangrove sejati yang terdapat di Indonesia, yakni 33 jenis [6]. Pada setiap umur hutan restorasi, jumlah jenis berkisar antara 4-6 jenis, sedangkan pada hutan sekunder berjumlah 9 jenis. 
Berdasarkan Tabel 1 diketahui bahwa penyebaran jenis pada hutan mangrove restorasi yang terbesar pada tingkat anakan pohon yaitu Rhizophora apiculata, Rhizophora stylosa dan Avicennia marina (100\%). Penyebaran terbesar pada tingkat pohon yaitu Rhizophora apiculata dengan penyebaran sebesar 100\%, Rhizophora mucronata sebesar 83,33\% dan diikuti oleh Avicennia marinasebesar 66,67\% . Tingginya penyebaran jenis-jenis mangrove kelompok Rhizophora spp. pada hutan restorasi karena jenis-jenis tersebut merupakan jenis yang ditanam, sedangkan tingginya penyebaran A. marina selain karena biji yang kecil sehingga mudah tersebar, juga karena tergolong jenis pionir yang mampu tumbuh pada daerah terbuka [7].

Tabel. 1. Sebaran setiap jenis pada setiap umur hutan restorasi dan hutan sekunder.

\begin{tabular}{|c|c|c|c|c|c|c|c|c|c|c|c|c|c|c|c|}
\hline \multirow{3}{*}{ No } & \multirow{3}{*}{ Jenis } & \multicolumn{10}{|c|}{ Umur Tegakan Hutan Restorasi (tahun) } & \multirow{2}{*}{\multicolumn{2}{|c|}{$\begin{array}{c}\text { Hutan } \\
\text { Sekunder }\end{array}$}} & \multirow{2}{*}{\multicolumn{2}{|c|}{$\mathrm{F}(\%)$}} \\
\hline & & \multicolumn{2}{|c|}{5} & \multicolumn{2}{|c|}{6} & \multicolumn{2}{|c|}{7} & \multicolumn{2}{|c|}{8} & \multicolumn{2}{|c|}{9} & & & & \\
\hline & & $\mathrm{A}$ & $\mathrm{P}$ & A & $\mathrm{P}$ & $\mathrm{A}$ & $\mathrm{P}$ & A & $\mathrm{P}$ & $\mathrm{A}$ & $\mathrm{P}$ & A & $P$ & A & $\mathrm{P}$ \\
\hline 1. & $\begin{array}{l}\text { Avicennia } \\
\text { marina }\end{array}$ & $\sqrt{ }$ & - & $\sqrt{ }$ & - & $\sqrt{ }$ & $\sqrt{ }$ & $\sqrt{ }$ & $\sqrt{ }$ & $\sqrt{ }$ & $\sqrt{ }$ & $\sqrt{ }$ & $\sqrt{ }$ & 100,00 & 66,67 \\
\hline 2. & $\begin{array}{l}\text { Avicennia } \\
\text { officinalis }\end{array}$ & - & - & - & - & - & - & - & - & - & - & $\sqrt{ }$ & $\sqrt{ }$ & 16,67 & 16,67 \\
\hline 3. & $\begin{array}{l}\text { Bruguiera } \\
\text { cylindrica }\end{array}$ & $\sqrt{ }$ & - & $\sqrt{ }$ & - & - & - & - & - & - & - & - & - & 33,33 & - \\
\hline 4. & $\begin{array}{l}\text { Bruguiera } \\
\text { gymnorhiza }\end{array}$ & - & - & - & - & - & - & - & - & - & - & $\sqrt{ }$ & $\sqrt{ }$ & 16,67 & 16,67 \\
\hline 5. & $\begin{array}{l}\text { Bruguiera } \\
\text { sexangula }\end{array}$ & - & - & - & - & - & - & - & - & - & - & $\sqrt{ }$ & $\sqrt{ }$ & 16,67 & 16,67 \\
\hline 6. & Ceriops tagal & - & - & - & - & - & - & - & - & - & - & $\sqrt{ }$ & $\sqrt{ }$ & 16,67 & 16,67 \\
\hline 7. & $\begin{array}{l}\text { Excoecaria } \\
\text { agallocha }\end{array}$ & - & - & - & - & - & - & $\sqrt{ }$ & $\sqrt{ }$ & - & - & - & - & 16,67 & 16,67 \\
\hline 8. & $\begin{array}{l}\text { Heritiera } \\
\text { littoralis }\end{array}$ & - & - & $\sqrt{ }$ & - & - & - & - & - & - & - & - & - & 16,57 & - \\
\hline 9. & $\begin{array}{l}\text { Lumnitzera } \\
\text { racemosa }\end{array}$ & - & - & & - & $\sqrt{ }$ & - & - & - & - & - & - & - & 16,67 & - \\
\hline 10. & $\begin{array}{l}\text { Rhizophora } \\
\text { apiculata }\end{array}$ & $\sqrt{ }$ & $\sqrt{ }$ & $\sqrt{ }$ & $\sqrt{ }$ & $\sqrt{ }$ & $\sqrt{ }$ & $\sqrt{ }$ & $\sqrt{ }$ & $\sqrt{ }$ & $\sqrt{ }$ & $\sqrt{ }$ & $\sqrt{ }$ & 100,00 & 100,00 \\
\hline 11. & $\begin{array}{l}\text { Rhizophora } \\
\text { mucronata }\end{array}$ & $\sqrt{ }$ & - & $\sqrt{ }$ & - & $\sqrt{ }$ & - & $\sqrt{ }$ & $\sqrt{ }$ & $\sqrt{ }$ & $\sqrt{ }$ & - & - & 33,33 & 83,33 \\
\hline 12. & $\begin{array}{l}\text { Rhizophora } \\
\text { stylosa }\end{array}$ & $\sqrt{ }$ & - & $\sqrt{ }$ & - & $\sqrt{ }$ & $\sqrt{ }$ & $\sqrt{ }$ & $\sqrt{ }$ & $\sqrt{ }$ & $\sqrt{ }$ & $\sqrt{ }$ & - & 100,00 & 50,00 \\
\hline 13. & $\begin{array}{l}\text { Scyphiphora } \\
\text { hydrophyllacea }\end{array}$ & - & - & - & - & - & - & - & - & - & - & $\sqrt{ }$ & $\sqrt{ }$ & 16,67 & 16,67 \\
\hline 14. & $\begin{array}{l}\text { Xylocarpus } \\
\text { granatum }\end{array}$ & - & - & - & - & - & - & - & - & - & - & - & $\sqrt{ }$ & - & 16,67 \\
\hline
\end{tabular}




\begin{tabular}{|c|c|c|c|c|c|c|c|c|c|c|c|c|}
\hline Jumlah jenis & 5 & 1 & 6 & 1 & 5 & 3 & 5 & 5 & 4 & 4 & 8 & \\
\hline Jumlah jenis & & 5 & & 6 & & 5 & & 5 & & 4 & & 9 \\
\hline
\end{tabular}

Keterangan: $\mathrm{A}=$ anakan pohon, $\mathrm{P}=$ tingkat pohon, $\mathrm{F}=$ sebaran jenis, $\sqrt{ }=$ ada, - = tidak ada.

Selain, kelompok jenis Rhizophora spp. yang ditanam, pada hutan hasil restorasi juga terdapat jenis-jenis lain, seperti kelompok Bruguiera spp., Excoecariaagallocha, Heritiera littoralis dan Lumnitzeraracemosa. Beberapa jenis yang ditemukan pada hutan hasil restorasi, namun tidak dijumpai pada hutan sekunder, yakni Bruguieracylindrica, Excoecariaagallocha, Heritieralittoralis dan Lumnitzeraracemosa. Hal ini menunjukan bahwa restorasi mangrove berhasil dalam pelestarian jenis-jenis mangrove.

\section{Komposisi Jenis}

Rhizopohora apiculata merupakan jenis yang dominan pada hutan mangrove hasil restorasi, sedangkan Avicennia marina dominan pada hutan sekunder (Tabel 2). Berdasarkan Tabel 2, pada setiap umurtegakan hutan restorasi, indeks nilai penting (INP) tertinggi terdapat pada jenis Rhizophora apiculata baik untuk tingkat anakan pahon maupun tingkat pohon. Pada umur 6 tahun, INP untuk tingkat anakan dan tingkat pohon adalah 116,04\% dan $191,34 \%$. Pada umur 7 tahun, INP untuk tingkat anakan dan tingkat pohon adalah 125,40\% dan 132,22\%. Pada umur 8 tahun, INP untuk tingkat anakan dan tingkat pohon adalah 103,03dan 107,43\%. Selanjutnya, pada umur 9 tahun, INP untuk tingkat anakan dan tingkat pohon adalah 113,85\% dan 139,70\%. Namun pada umur tegakan 5 tahun, INP tertinggi terdapat pada jenis Rhizophora apiculata untuk tingkat anakan pohon yaitu $111,52 \%$ sedangkan untuk tingkat pohon INP tertinggi terdapat pada jenis Avicennia marina yaitu $300 \%$.

Pada hutan sekunder,Avicennia marina memiliki INP tertinggi baik untuk anakan pohon maupun pohon yang secara berturut turut adalah $47,82 \%$ dan $118,86 \%$. Tingginya INP pada Rhizophora apiculata pada hutan hasil restorasi disebabkan karena Rhizophora apiculata dapat tumbuh dengan baik diakibatkan karakteristiknya yang dapat tumbuh dengan baik pada daerah berlumpur dengan tingkat salinitas yang tinggi, kemampuan bertahan terhadap perendaman oleh pasang surut dan memiliki akar nafas [7].

\section{Pembahasan}

Kekayaan jenis dan kerapatan pohon pada beberapa tipe hutan mangrove disajikan pada Tabel 3. Berdasarkan Tabel 3 tersebut diketahui bahwa hutan restorasi bekas lahan tambak di lokasi penelitian memiliki jenis lebih tinggi dibandingkan kawasan pesisir dan tambah di Banda Aceh, namun lebih rendah dibandingkan dengan hutan mangrove lainnya di Sumatera Utara. Namun demikian, kekayaan jenis hutan mangrove hasil restorasi telah mencapai 77,8\% dari jenis hutan mangrove sekunder yang berada di sekitar lokasi hutan restorasi. Oleh karena itu, restorasi mangrove pada lahan bekas tambak berpotensi di dalam konservasi jenis-jenis mangrove.

Tabel.2. Indeks nilai penting (INP) setiap jenis pada hutan hasil restorasi dan hutan sekunder.

\begin{tabular}{|c|c|c|c|c|c|c|c|c|c|}
\hline \multirow{2}{*}{ No } & \multirow{2}{*}{$\begin{array}{c}\text { Umur } \\
\text { Tegakan }\end{array}$} & \multirow{2}{*}{ Jenis } & \multicolumn{2}{|c|}{$\mathrm{KR}(\%)$} & \multicolumn{2}{|c|}{$\mathrm{FR}(\%)$} & \multirow{2}{*}{$\frac{\mathrm{DR}(\%)}{\mathrm{P}}$} & \multicolumn{2}{|c|}{$\operatorname{INP}(\%)$} \\
\hline & & & $\mathrm{A}$ & $P$ & A & $\mathrm{P}$ & & $\mathrm{A}$ & $\mathrm{P}$ \\
\hline \multirow[t]{6}{*}{1} & 5 tahun & Avicennia marina & 25,34 & 100,0 & 13,73 & 100,0 & 100,0 & 39,07 & 300,00 \\
\hline & & Bruguiera sexangula & 3,31 & - & 3,91 & - & - & 7,22 & - \\
\hline & & Rhizophora apiculata & 64,46 & - & 47,06 & - & - & 111,52 & - \\
\hline & & Rhizophora mucronata & 3,24 & - & 15,69 & - & - & 18,93 & - \\
\hline & & Rhizophora stylosa & 3,65 & - & 19,61 & - & - & 23,26 & - \\
\hline & & Jumlah & 100,0 & 100,0 & 100,0 & 100,0 & 100,0 & 200,0 & 300,0 \\
\hline 2 & 6 tahun & Avicennia marina & 2,72 & 5,54 & 10,77 & 14,29 & 36,10 & 13,49 & 58,84 \\
\hline
\end{tabular}




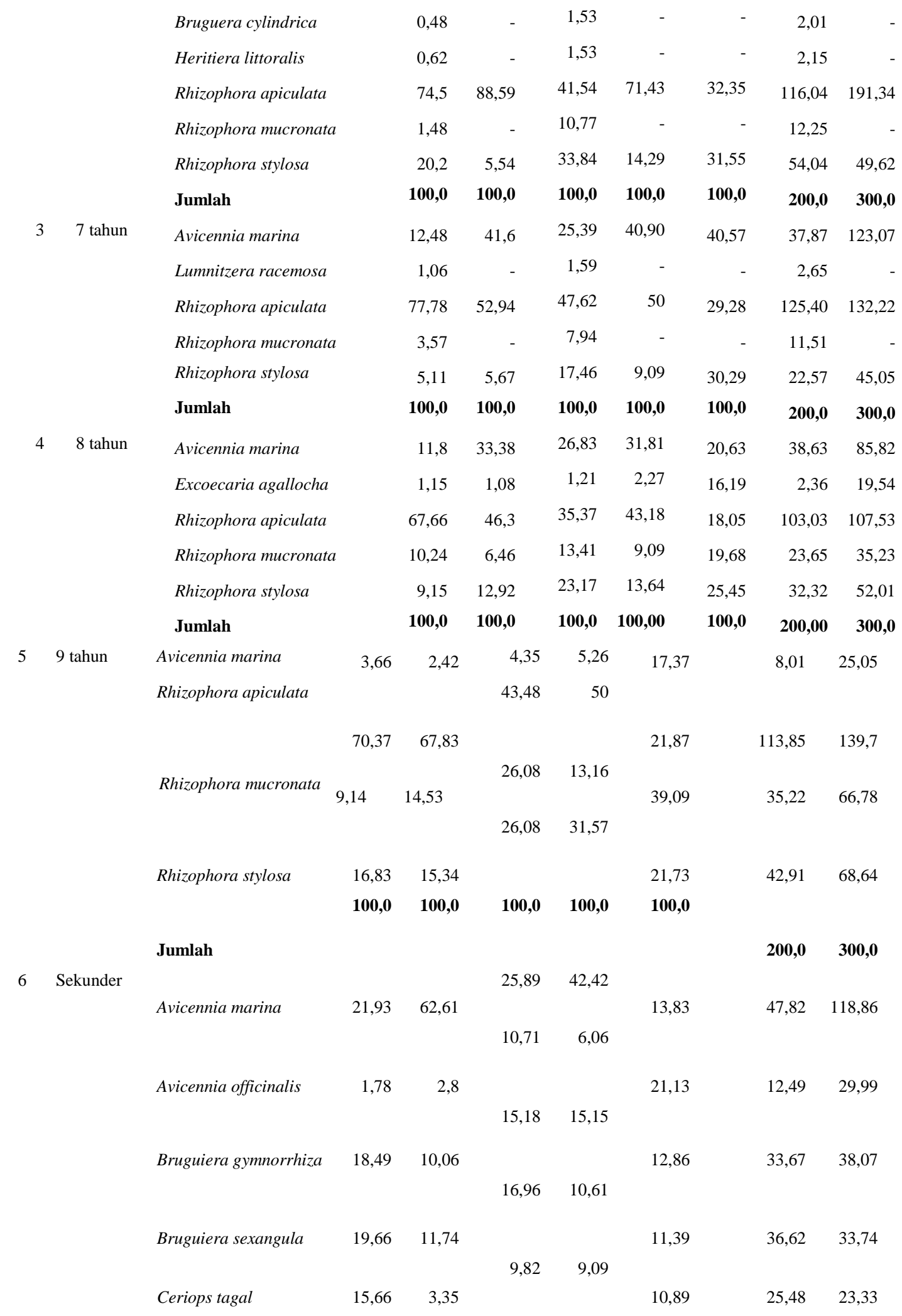




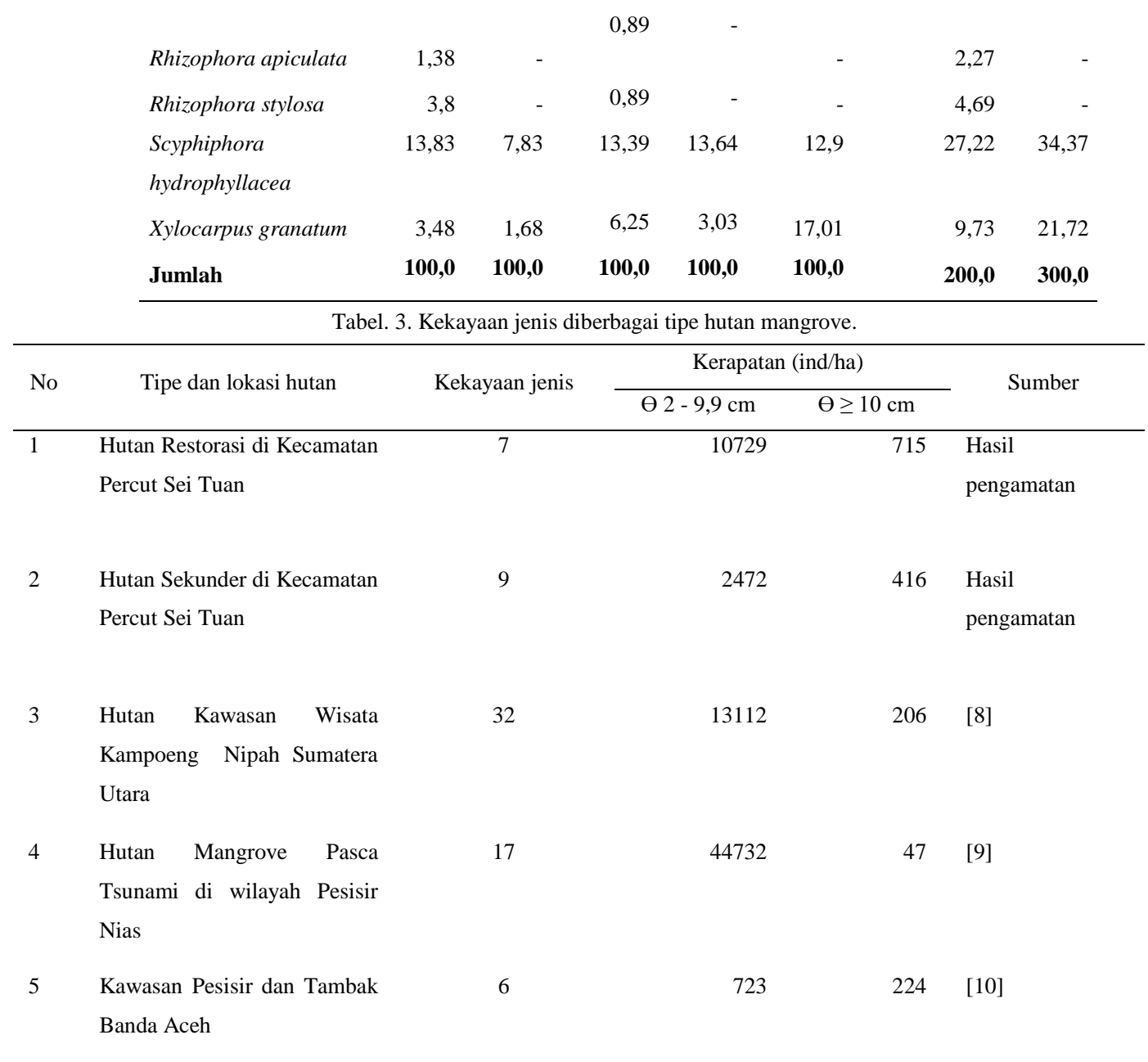

Hutan restorasi pada lahan bekas tambak memiliki kerapatan yang sangat tinggi pada tegakan permudaanya yaitu diatas $\geqslant 7.500 \mathrm{ind} / \mathrm{ha}$ untuk semai dan pancang, sedangkan untuk hutan sekundernya memilki kerapatan yang sedang yaitu 2000-4000 ind/ha untuk semai dan pancang [11]. Begitu juga dengan hutan kawasan wisata Kampoeng Nipah [8], dan hutan mangrove pasca tsunami di wilayah pesisir Nias [9] yang memilki kerapatan yang sangat tinggi.

\section{Kesimpulan dan Saran}

Hutan mangrove di Kecamatan Percut Sei Tuan disusun oleh 14 jenis mangrove sejati dan sebanyak 7 jenis diantaranya terdapat pada hutan mangrove hasil restorasi. Dengan demikian, kegiatan restorasi mangrove mampu melestarikan keanekaragaman jenis-jenis mangrove. Sehingga restorasi mangrove pada lahan bekas tambak perlu dipromosikan sebagai bagian dari pemulihan kawasan pesisir pantai yang telah terganggu atau rusak.

\section{Ucapan Terima Kasih}

Penulis menyampaikan terima kasih kepada pimpinan USU dan LP USU yang telah membiayai penelitian ini melalui penelitian BPPTN USU tahun 2016 sesuai dengan kontrak No. 6049/UN5.1.R/PPM/2016, tanggal 19 Juli 2016 dengan ketua peneliti Onrizal, S.Hut., M.Si., Ph 


\section{Referensi}

[1] Murdiyarso, D., Purbopuspito, J., Kauffman, J. B., Warren, M. W., Sasmito, S. D., Donato, D. C., Manuri, S., Hanuri, K., Taberima., \& Kurnianto, S. 2015. The potential of Indonesian mangrove forests for global climate change mitigation. Nature Climate Change, 5(12), 10891092.

[2] Giri, C., Ochieng, E., Tieszen, L. L., Zhu, Z., Singh, A., Loveland, T., Masek, J., \& Duke, N. 2011. Status and distribution of mangrove forests of the world using earth observation satellite data. Global Ecology and Biogeography, 20(1), 154-159.

[3] Ilman, M., Dargusch, P., Dart, P\& Onrizal. 2016. A historical analysis of the drivers of loss and degradation of Indonesia's mangroves. Land Use Policy, 54, 448-459.

[4] Onrizal., \& Kusmana, C. 2008. Studi ekologi hutan mangrove di pesisir Sumatera Utara. Biodersivitas 9, (1): 25-29.

[5] Onrizal., \& Mansor, M. 2016. Status of coastal forests of the Northern Sumatra In 2004's tsunami catastrophe. Biodiversitas Journal of Biological Diversity, 17(1), 44-54.

[6] Noor, Y. R., \& Khazali, I. N. N. Suryadiputra. 2006. Panduan Pengenalan Mangrove di Indonesia. PHK/WI-IP, Bogor.

[7] Onrizal., Hutabarat, F., Barus, T., \& Mansor, M. 2009. Karbon stock and macrobenthic fauna diversity at various land-use of mangrove in North Sumatra, Indonesia. Proceeding Of The International Conference On Natural And Environmental Sciences 2009 (ICONES'09) PP 141147.

[8] Onrizal., \& Kusmana, C. 2009. Struktur dan kekayaan jenis tumbuhan mangrove pasca-tsunami di pulau nias [Structure and species richness of mangroves plant post-tsunami in Nias Island]. Berita Biologi, 9(4): 359-364.

[9] Onrizal, Sulistiyono, N., Patana, P., \& Mansor, M. 2016. Implikasi pengelolaan hutan terhadap karbon mangrove di Sumatera Utara. Prosiding Seminar Nasional Penguatan Pengajaran dan Penelitian Perubahan Iklim: Bridging Gap Implementasi Kebijakan Mitigasi dan Adaptasi di Tingkat Nasional dan Subnasional. 25-31.

[10] Sosia, P. Y., Rahmadhani, T., \& Nainggolan, M. 2014. Mangrove Siak \& Kepulauan Meranti. Environmental \& Regulatory Compliance Division Safety, Healty \& Environment Departement.

[11] Departemen Kehutanan Direktorat Jenderal Rehabilitasi Lahan dan Perhutanan Sosial. 2005. Pedoman Inventarisasi dan Identifikasi Lahan Kritis Mangrove. 